\title{
MICROSTRUCTURE OF A STELLITE/STEEL CLAD INTERFACE
}

\author{
M. G. Burke, T. G. Hicks and M.W. Phaneuf* \\ Bechtel Bettis, Inc., West Mifflin, PA 15122 \\ *Fibics, Inc., Ottawa, Ontario, Canada
}

Stellite 6 is a Co-28Cr-4W-1.1C hardfacing alloy, which exhibits excellent wear resistance as well as good oxidation and corrosion performance. Stellite hardfacing is generally applied to steel via an arc welding process, which typically involves some melting of the steel substrate, so that the assolidified microstructure will include a zone of intermixing as well as the as-solidified Stellite. The resulting microstructure can vary significantly over $\sim 20 \mu \mathrm{m}$, which may lead to a local variation in the properties of the as-deposited material.(1) The microstructure developed as a result of the hardfacing process was characterized in detail using a range of characterization techniques, including light optical microscopy (LOM), electron probe microanalysis (EPMA), analytical electron microscopy (AEM) and focused ion beam (FIB) techniques. Electron-transparent specimens prepared using conventional ion-polishing and site-specific FIB techniques were evaluated in Philips CM12 and CM300 FEG AEMs that were equipped with Oxford Instruments energy dispersive $\mathrm{X}$-ray spectrometers (EDS) for microanalysis.

EPMA analyses of cross-section samples revealed several distinct zones: a) the base steel; b) a narrow, apparently single phase band; c) a two-phase solidification structure. A localized layer containing $\sim 40 \% \mathrm{Fe}$ and $\sim 2 \mu \mathrm{m}$ in thickness was identified in the intermixing zone adjacent to the fusion line. AEM analysis revealed the presence of a lamellar, pearlitic-type $\mathrm{M}_{3} \mathrm{C}$ carbide structure in the base steel in the vicinity of the fusion line, Figs. 1 and 2. Further analysis of the near-fusion line microstructure of the Stellite deposit revealed a complex multi-phase microstructure consisting of: a) a martensite-like structure with hexagonal intralath $\varepsilon$ Co-type precipitates $\sim 10$ to $30 \mathrm{~nm}$ in length adjacent to the fusion line; b) a body centered cubic (bcc) Fe-Co-enriched $\alpha$ phase with an interconnected Cr-enriched $\alpha^{\prime}$ phase located beyond the martensitic phase; and c) fine ( 20 to 150 $\mathrm{nm}) \mathrm{M}_{23} \mathrm{C}_{6}$ carbides within the fcc Stellite matrix. The Cr-enriched phase exhibited a morphology and size consistent with the $\alpha^{\prime}$ bcc phase formed during aging in Fe-Cr-Co alloys (associated with severe hardening and embrittlement). The Fe-Cr-Co system contains a metastable miscibility gap, so that the single-phase bcc $\alpha$ alloy aged within the gap will spinodally decompose into the $\mathrm{Fe} / \mathrm{Co}-$ rich $\alpha$ and Cr-rich $\alpha^{\prime}$ phases.(2-4) The results of the STEM-EDS microanalyses and the EPMA quantitative analyses showed that the interfacial region contained significant amounts of $\mathrm{Fe}, \mathrm{Co}$ and Cr. The Fe dilution into the Stellite extended over $20 \mu \mathrm{m}$ into the hardfacing deposit. It is this Fe dilution that promotes the complex multi-phase microstructure in the near-fusion line zone. Further analysis of a delaminated hardfacing interface revealed that the separation was associated with the complex fusion zone microstructure. The martensitic and modulated microstructures are both associated with increased hardness and brittleness. Experience has shown successful performance of Stellite on steel in wear applications, but a sensitivity to delamination in this region for weld repairs. In this study, the FIB technique successfully enabled the acquisition of AEM specimens at the fusion line so that the fine-scale microstructure could be evaluated with precise site specificity.

\section{References}

1. S. Atamert and H.D.K.H. Bhadeshia, Met. Trans. A, 20A (1989) 1037.

2. F. Zhu, H. Wendt and P. Haasen, Scripta Met., 16 (1982) 1175.

3. S.S. Brenner, P.P. Camus, M.K. Miller and W.A. Soffa, Acta Met., 32 (1984) 1217. 
4. L.L. Horton, M.K. Miller and S. Spooner, Proc. $44^{\text {th }}$ Annual Meeting of EMSA, G.W. Bailey, ed., (San Francisco Press, 1986) 580.

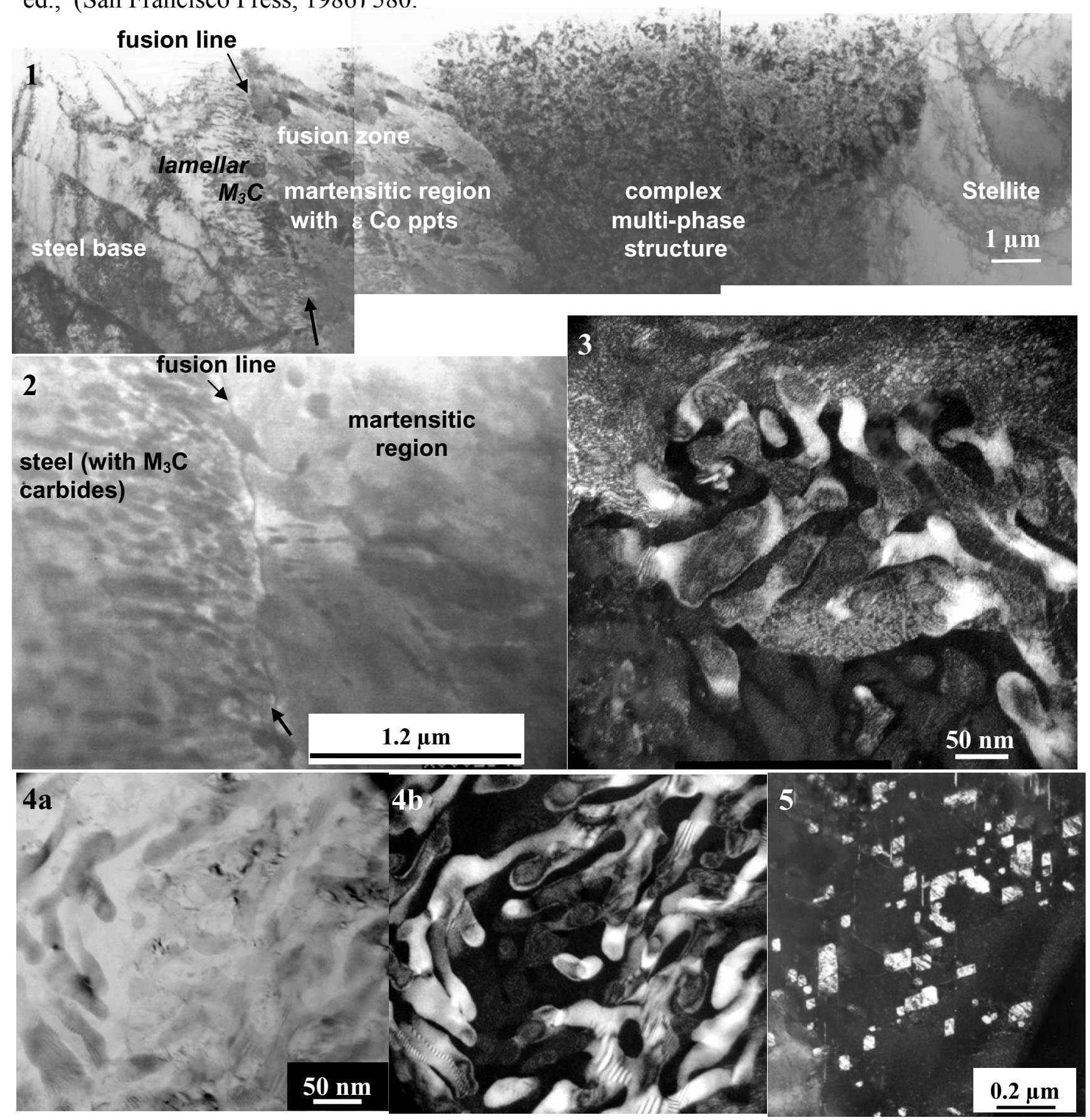

Fig. 1. TEM montage of the steel-fusion zone-Stellite cross-section sample prepared using FIB. Fig. 2. STEM image of the fusion boundary, with lamellar $\mathrm{M}_{3} \mathrm{C}$ carbides present in the steel adjacent to the boundary, and a highly dislocated martensitic structure in the fusion zone. Fig. 3. Dark-field TEM image of the complex Cr-enriched phase resembling the $\alpha^{\prime}$ phase in Fe-CrCo alloys. Fig. 4. (a) Bright-field and (b) dark-field TEM images of the complex $\alpha^{\prime}$-type Crenriched phase. Fig. 5. Dark-field TEM image of the fine Cr-rich $\mathrm{M}_{23} \mathrm{C}_{6}$ carbides formed in the face centered cubic matrix of the Stellite beyond the multi-phase fusion zone. 